\title{
GEOVISUALIZAÇÃO E GEOCOLABORAÇÃO DO PATRIMÔNIO HISTÓRICO DE CABO FRIO-RJ
}

\author{
Geovisualization and geocolaboration of the historical patrimony of Cabo Frio-RJ \\ Geovisualización y geocolaboración del patrimonio histórico de Cabo Frío-RJ
}

\author{
Ivan Rollas da Silva \\ Coordenador Técnico em GIS na Secretaria de Fazenda Municipal de Cabo Frio \\ ivanrollas260@hotmail.com \\ Matheus Pereira Libório \\ Professor do Curso de Especialização de Geoprocessamento - PUC MG \\ m4th32s@gmail.com
}

Artigo enviado para publicação em 02/10/2018 e aceito em 01/11/2018

DOI: $10.12957 /$ tamoios.2018.37558

\section{Resumo}

A falta de documentação e sistematização do patrimônio histórico-cultural, ou mesmo sua disponibilidade de forma pouco atraente ou lúdica, desconecta a população do legado arquitetônico, artístico, cultural e histórico, o que significa a perda da afetividade patrimonial e do compromisso. em conservá-lo. Nesse contexto, o objetivo desta pesquisa foi promover a educação do patrimônio histórico-cultural da cidade de Cabo Frio RJ. Trabalhos existentes na literatura voltados para a educação patrimonial histórico-cultural exploram o espaço geográfico de forma não interativa. Superamos essa limitação por meio do desenvolvimento de ferramentas bidirecionais de geovisualização que permitem ao usuário explorar e colaborar com o patrimônio histórico-cultural, utilizando-se do espaço geográfico de forma interativa. Mostramos que o desenvolvimento dessas ferramentas demanda pouco tempo e/ou recursos financeiros sendo, portanto, viável para quaisquer municípios interessados em implementar a solução. Contribuímos para a educação patrimonial histórico-cultural ao apresentar uma inovação que é econômica e, ao mesmo tempo, interativa e colaborativa.

Palavras-chave: Geoprocessamento; Geovisualização; Geocolaboração; Educação Patrimonial Histórico-Cultural.

\section{Abstract}

The lack of documentation and systematization of the historical-cultural patrimony, or even its availability in an unattractive or playful manner, disconnects the population from the architectural, artistic, cultural and historical legacy, which means the loss of the patrimonial affectivity and of the commitment in conserving it. In this context, the goal of this research was to promote the Cabo Frio RJ city's historical-cultural heritage education. Existing works in the literature focused on the cultural-historical patrimony education, explore the geographic space without interacting with the user. We overcome this limitation through developing a bidirectional geo-visualization tools, which allow the user to explore and collaborate with historical-cultural heritage using the geographic space interactively. We have shown that these tools development require low time and financial resources, and thus its feasibility for any municipalities interesting into implement the solution. We contribute to historical-cultural heritage education by presenting an innovation that is both economical and interactive and collaborative.

Keywords: Geoprocessing; Geovisualization; Geocolaboration; Historical-Cultural Heritage Education.

\section{Resumen}

La falta de documentación y sistematización del patrimonio histórico-cultural, o incluso su disponibilidad de forma poco atractiva o lúdica, desconecta a la población del legado arquitectónico, artístico, cultural e histórico, lo que significa la pérdida de la afectividad patrimonial y del compromiso. en conservarlo. En ese contexto, el objetivo de esta investigación fue promover la educación del patrimonio histórico-cultural de la ciudad de Cabo Frio RJ. Los trabajos existentes en la literatura orientados a la educación patrimonial histórico-cultural exploran el espacio geográfico de forma no interactiva. Superamos esta limitación a través del desarrollo de herramientas bidireccionales de geovisualización que permiten al usuario explorar y colaborar con el patrimonio histórico-cultural, utilizando el espacio geográfico de forma interactiva. Hemos mostrado que el desarrollo de estas herramientas demanda poco tiempo y / o recursos financieros siendo, por lo tanto, viable para cualesquiera municipios interesados en implementar la solución. Contribuimos a la educación patrimonial histórico-cultural al presentar una innovación que es económica y, a la vez, interactiva y colaborativa.

Palabras clave: Geoprocesamiento; Geovisualización; Geocollaboration; Educación Patrimonial Histórico-Cultural. 


\section{INTRODUÇÃO}

O presente artigo se insere no contexto da educação patrimonial e, através da criação de ferramentas geotecnológicas, busca assumir um papel de difusora e propagadora da cidade (TOLENTINO, 2012). Cidade esta que é reconhecida como a maior e mais duradoura realização da cultura, não havendo indícios de sua substituição por outro artefato humano no planeta (PERES, POLIDORI E TOMIELLO, 2015).

Propiciar visibilidade ao patrimônio imaterial local e facilitar o acesso à informação, de forma clara e objetiva faz parte de esforços para a melhor compreensão dos processos de evolução urbana. A forma que ocorre a evolução urbana tem sido possível através do manejo adequado dos dados disponíveis. Por exemplo, por meio de análises espaciais avançadas que associam múltiplas variáveis e atributos urbanos (PERES, POLIDORI E TOMIELLO, 2015).

Para demonstrar como as geotecnologias podem contribuir para a difusão da educação patrimonial, fez-se a escolha por Cabo Frio, no estado do Rio de Janeiro. A cidade de Cabo Frio é uma das mais antigas do Brasil. Seu descobrimento, provavelmente por Américo Vespúcio, é datado entre dezembro de 1503 e janeiro de 1504. Cabo Frio foi a primeira feitoria do Brasil (BERANGER, 1962) e concentra, até hoje, grande número de imóveis de interesse histórico. A cidade conta com imóveis de interesse histórico em níveis federal, estadual e municipal, tombados pelo Instituto do Patrimônio Histórico e Artístico Nacional (IPHAN).

A partir da geotecnologia proposta, com a preservação, integração e educação da comunidade seja ela local ou não, que se favoreça o conhecimento, preservação e valorização das edificações de interesse histórico-cultural. E se fomente a criação de novos projetos para sua manutenção ou melhoramento. Tal inciativa se justifica primeiramente porque, mesmo havendo consenso sobre a necessidade da preservação do patrimônio histórico cultural, pode-se reconhecer diversos exemplos de descaso com o patrimônio pré-existente, que foi desvalorizado em detrimento da pressão do mercado imobiliário (PERES, POLIDORI E TOMIELLO, 2015). Em segundo lugar, pode-se reconhecer também a ineficiência nos processos educativos voltados para a preservação da arte histórica. Entre elas, a arquitetura de prédios, sítios e monumentos históricos. Em terceiro lugar, pode-se notar a transformação da memória em mercadoria, tornando os centros históricos em cenários para "selfies" ou espetáculos programados (FERRAZ, 2017).

A falta de documentação histórica, assim como sua a sua sistematização, ou mesmo, tal conteúdo histórico disponibilizado de maneira mais atrativa ou lúdica, levanos a pensar em sistemas de visualização e colaboração com um olhar diferenciado sobre a educação patrimonial (TOLENTINO, 2012; ALLEN, 2014). A não preservação de tais patrimônios é um problema de educação urbana. Entende-se como o não conhecimento ou falta de apropriação. Para preservar ou valorizar precisa-se antes de tudo conhecer, interagir ou um retorno ao passado, de maneira que se torne um elemento estruturante de identidade local (RIBEIRO FILHO; PASSOS; DE MOURA PAULINO, 2010). A falta desta identidade, junto ao pouco ou a quase inexistência de materiais de conteúdo histórico de relevância principalmente ao nível popular ou de fácil acesso à população local e turística é o cerne do problema tratado neste artigo.

A solução do problema da preservação do patrimônio histórico cultural passa pela sua divulgação nos meios educativos. A solução do problema da preservação da arte histórica, entre elas, a arquitetura de prédios, sítios e monumentos históricos, passa pela aplicação de métodos que concebam projetos de arquitetura e urbanismo que mantenham a unidade do entorno histórico valorizado (PERES; POLIDORI; TOMIELLO, 2015). 
O não entendimento dos conjuntos históricos edificados e sua valorização é um retrato do desinteresse da população com o seu patrimônio cultural. O ambiente urbano é, então, descartado como fonte de identidade e pertencimento (PERES; POLIDORI; TOMIELLO, 2015). A comunidade local se desconecta do legado arquitetônico, artístico, cultural e histórico, perdendo sua afetividade patrimonial e seu comprometimento com a sustentabilidade social, ambiental, econômica e de conservação do patrimônio (MOURA, 2008).

A representação digital do ambiente urbano é uma tentativa de resgate dessa afetividade e comprometimento com o patrimônio. Por meio da disponibilização de conhecimentos ou recursos de simulação de cenários, a representação digital vem se tornando um meio para a valorização da memória e da identidade urbana, pois contribui para a elaboração de planos e projetos voltados ao cuidado do ambiente urbano (PERES, POLIDORI E TOMIELLO, 2015; CONCEIÇÃO SILVA, 2017).

A representação digital vai além de um caráter cosmético, tendo como função primária a difusão de olhares e perspectivas diversas sobre as cidades e seus "Centros Históricos" (FERRAZ, 2017), a difusão de conhecimentos sobre a cidade, a democratização da informação e o empoderamento o cidadão (MENEGUETTE, 2014).

Observa-se que os problemas derivados do distanciamento da população e o patrimônio histórico são conhecidos, sendo, na sua origem, associados à desinformação da população (MOURA, 2008; RIBEIRO FILHO; PASSOS; DE MOURA PAULINO, 2010; ALLEN, 2014). As tecnologias de informação e comunicação, como a geovisualização e geocolaboração (MENEGUETTE, 2014), têm sido importantes para disseminar conhecimentos tangíveis ou intangíveis (PERES; POLIDORI; TOMIELLO, 2015; SILVA; LIBÓRIO; LAUDARES, 2016; Ferraz, 2017; GUALBERTO et al., 2017), mas seu uso na educação patrimonial ainda é incipiente (CONCEIÇÃO SILVA, 2017). Iniciativas como, por exemplo, de roteiros geoturísticos como instrumentos de educação patrimonial em Belém, são pouco avançadas, disponibilizam informações de modo unidirecional e sem mobilidade (BARROS; SERRA, 2018).

O objetivo desta pesquisa é produzir geotecnologias para divulgação, disponibilização e popularização do patrimônio histórico cultural da cidade de Cabo Frio. A geovisualização e a geocolaboração sustentam a solução que busca, chamando a atenção e interesse da população, contribuir para a valorização e preservação do patrimônio histórico cultural urbano.

\section{METODOLOGIA}

Para o presente artigo, além da revisão bibliográfica, apresentamos um estudo de caso onde dois protótipos são desenvolvidos. Foi adotado o Google My Maps exclusivo para geovisualização e, a plataforma Appsheet, para construção de um aplicativo voltado tanto à geovisualização como à geocolaboração, porém ambos podem ser acessados por desktops e dispositivos móveis (celulares e tablets).

A solução de geovisualização e geocolaboração foi desenvolvida em três fases: (A) prototipação da plataforma Appsheet em dispositivos móveis; (B) prototipação de mapa colaborativo na plataforma Google My Maps; e (C) criação de site de divulgação e organização dos protótipos.

Na Fase (A), o desenvolvimento APP YBY Cabo Frio (YBY significa em Tupi terra, chão em que se pisa (NAVARRO, 2013) ocorreu em cinco etapas, dentre os quais a (1) criação da planilha, (2) importação de dados, (3) ajuste de aparência, (4) inserção de registros e (5) publicação. Na Etapa 1, utilizou-se o GoogleDocs e a Google Spreadsheet 
para construir a Tabela 1, que contem os campos nome, descrição, foto, endereço, Address e visitar.

TABELA 1: PLANILHA DE DADOS

\begin{tabular}{|l|l|l|}
\hline Coluna & Tipo & Características \\
\hline Nome & Name & $\begin{array}{l}\text { Informação obrigatória. Contém o título do registro. O tipo } \\
\text { Name é estabelecido pelo Appsheet para indicar quais } \\
\text { informações serão apresentadas como títulos. }\end{array}$ \\
\hline Descrição & Texto Longo & $\begin{array}{l}\text { Informação obrigatória. Contém uma descrição livre sobre o } \\
\text { registro. }\end{array}$ \\
\hline Photo & Image & $\begin{array}{l}\text { Informação obrigatória. Imagem representativa do registro. } \\
\text { Esta coluna recebeu o nome em inglês para ser reconhecida } \\
\text { automaticamente como uma coluna do tipo image e assim } \\
\text { permitir a visualização das imagens desta no protótipo. As } \\
\text { imagens foram inseridas posteriormente no próprio aplicativo. }\end{array}$ \\
\hline Endereço & Texto & $\begin{array}{l}\text { Contém o endereço por extenso do registro: Rua, número, } \\
\text { bairro. }\end{array}$ \\
\hline Address & Latlong & $\begin{array}{l}\text { Informações obrigatórias. Contém as coordenadas geográficas } \\
\text { (latitude e longitude). São as informações extraídas desta } \\
\text { coluna que georreferenciam os registros no mapa. Para } \\
\text { preenchimento das informações no aplicativo este item é } \\
\text { obtido automaticamente após definição da localização no no } \\
\text { mapa. O título da coluna em inglês permite com que seja } \\
\text { reconhecida pelo Appsheet e também a diferencia da coluna } \\
\text { Endereço. }\end{array}$ \\
\hline Visitar & $\begin{array}{l}\text { Contém as informações sim ou não para identificar se os } \\
\text { registros fazem parte do Projeto Visitar. Esta informação não } \\
\text { é solicitada para novos registros. }\end{array}$ \\
\hline
\end{tabular}

Fonte: Autores.

Na Etapa 2, adicionamos a Tabela 1 à plataforma Appsheet via Google Drive, optando por autorizar que usuários apenas adicionem novos registros, sem permitir alterações dos registros anteriores. Ao inserir a Tabela 1, os registros são georreferenciados a partir da coluna Address. Na Etapa 3, definimos as características de experiência do usuário (UX) do aplicativo, possibilitando dois tipos de visualização: por lista e/ou por mapa. Na Etapa 4, inserimos e associamos informações do patrimônio histórico aos pontos georreferenciados por meio do upload da Tabela 1 via Google Drive. Na Etapa 5, testamos e a publicamos o APP na World Wide Web.

Na Fase (B), o desenvolvimento do protótipo YBY Cabo Frio MyMaps ocorreu em quatro etapas: (1) carregamento de dados, (2) configurações e layout, (3) inserção de roteiros e (4) publicação na web. Na Etapa 1, importamos os dados, do serviço em nuvem Google Drive, buscando a Tabela 1, já atualizada e com os novos registros. Na Etapa 2, configuramos a aparência do mapa, como, por exemplo, o ajuste da forma, cor dos marcadores e layout da imagens. Na Etapa 3, inserimos as sugestões de roteiros a serem realizados a pé conforme o projeto "Caminhos da História" do plano de cultura do município, projeto de Lei $\mathrm{n}^{\circ}$ 017/2018 (Cabo Frio, 2018). Na Etapa 4, testamos e publicamos o protótipo.

Na Fase (C) o desenvolvimento do site de divulgação e organização dos protótipos ocorreu em 4 etapas. Na Etapa (1), criamos o logotipo e o nome do APP. Na Etapa 2, elaboramos a identidade visual do site. Na Etapa 3, inserimos fotos, textos e links de 
download do APP, bem como o passo a passo para download e utilização dos protótipos e visualização dos conteúdos e dos mapas. Na Etapa 4, publicamos a página na Web.

\section{RESULTADOS}

Na tela inicial do YBY Cabo Frio (Figura 1) visualiza-se a área de estudo e seus respectivos pontos históricos, marcados com pontos georreferenciados em cor laranja, os quais possuem um registro fotográfico e suas respectivas informações históricas.

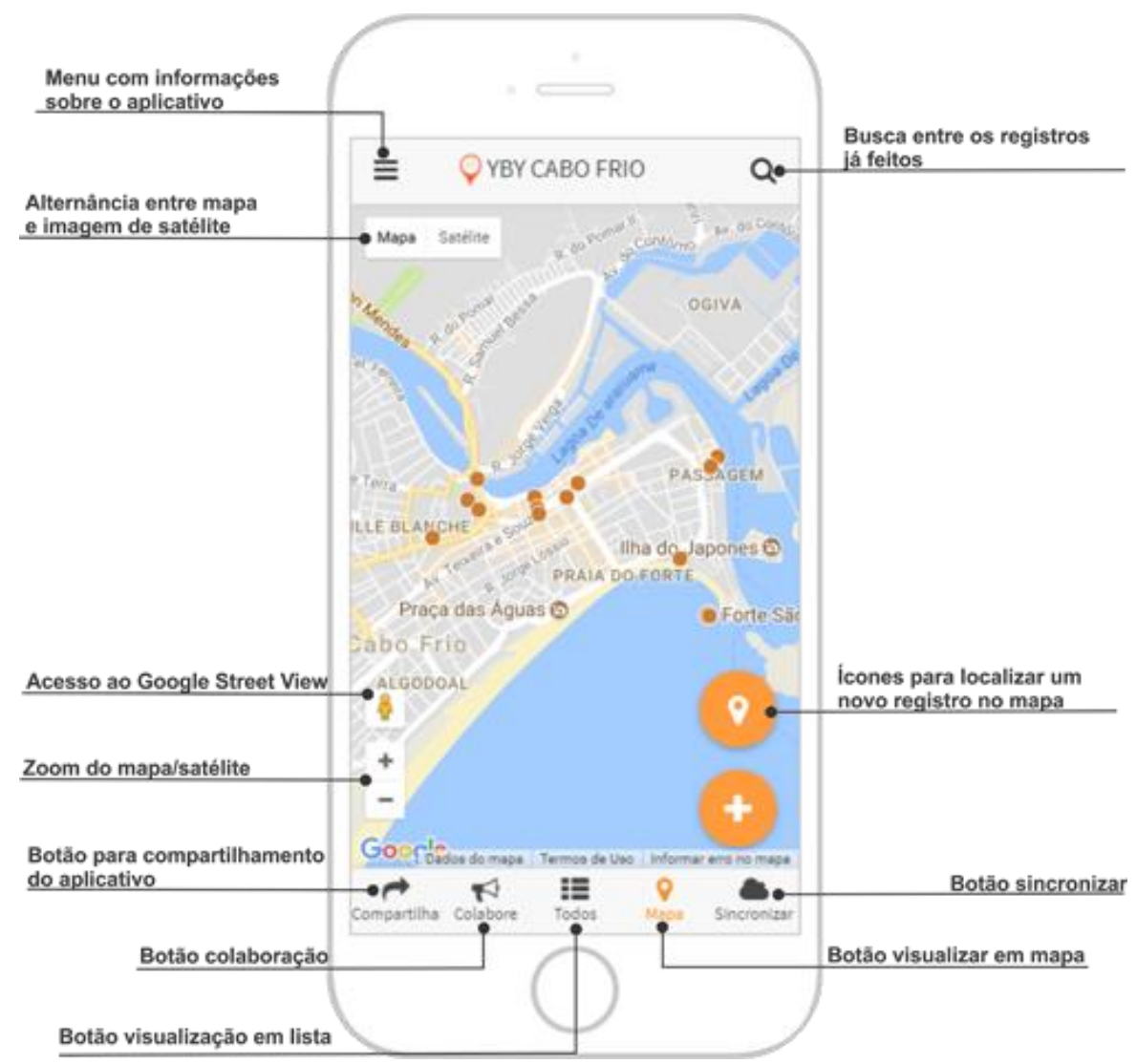

Figura 1. Tela inicial do aplicativo.

Detalhamos cada função apresentada na tela do aplicativo (a) visualização em lista; (b) visualização em mapa com registro selecionado; (c) detalhe do registro; (d) formulário de geocolaboração na Figura 2. 

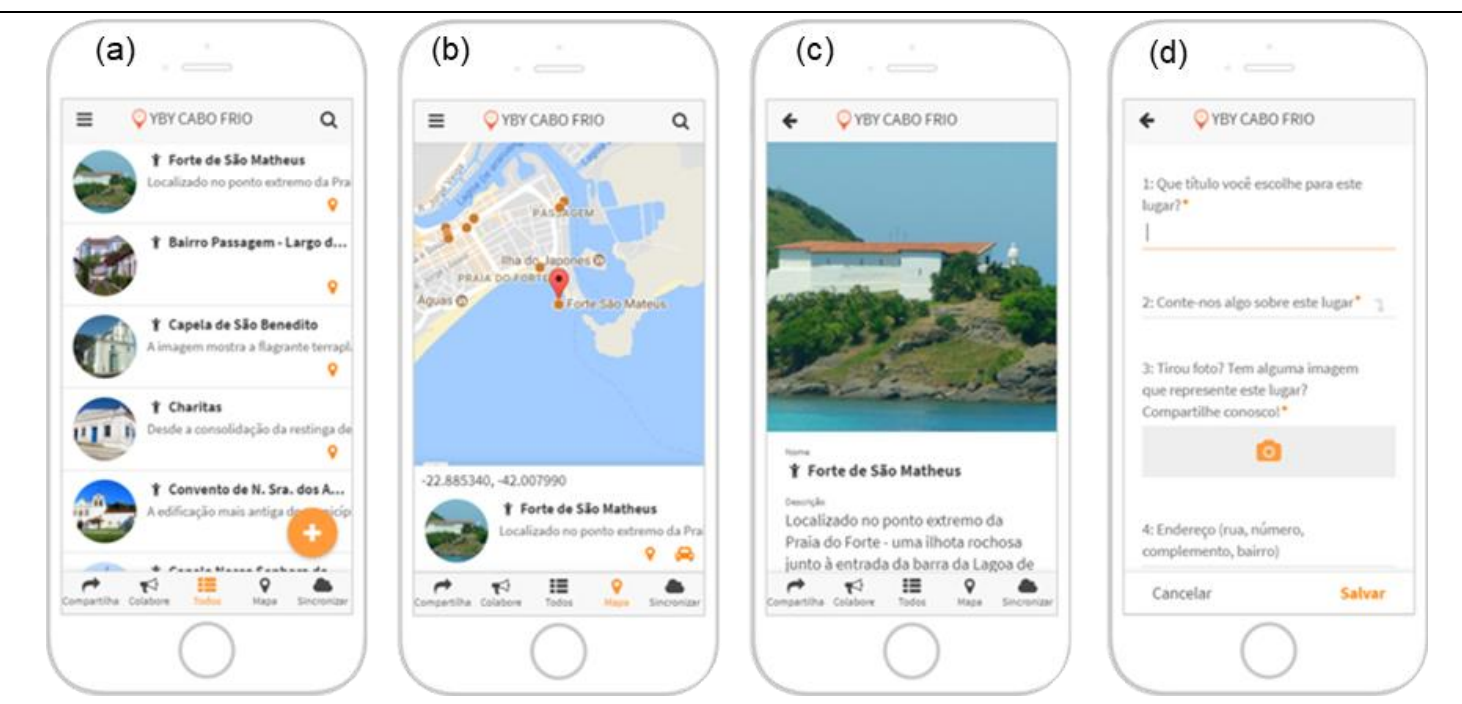

Figura 2. Telas do aplicativo

O protótipo permite utilizar funções como a visualização de imagem de satélite, a localização de pontos de interesse, a sua história e também a colaboração, através do botão "colabore", onde o usuário pode dar um título para o local, contar algo sobre ele e inserir uma foto, como mostram as telas (a, b, c e d) da Figura 2.

Na tela inicial do protótipo, apresentada na Figura 3, visualiza-se a área de estudo Cabo Frio com seus respectivos marcadores do patrimônio histórico cultural.

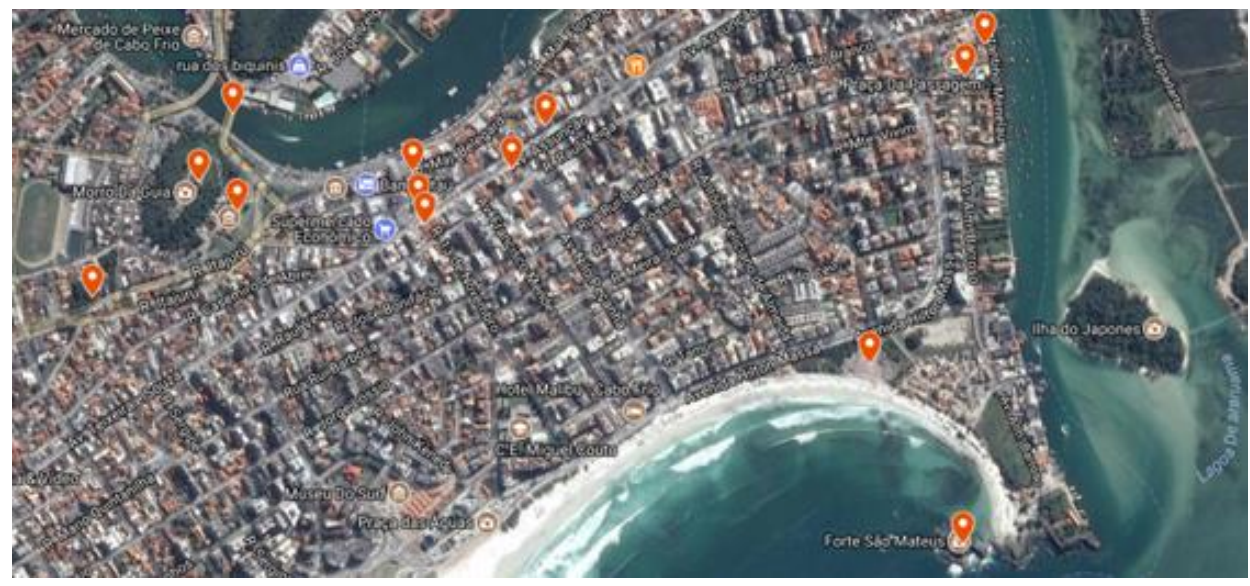

Figura 3. Página inicial do protótipo Google MyMaps

$\mathrm{Na}$ Figura 4, cada monumento do patrimônio histórico cultural é simbolizado por um marcador na cor laranja e associado a um registro fotográfico, assim como a uma narrativa histórica. 


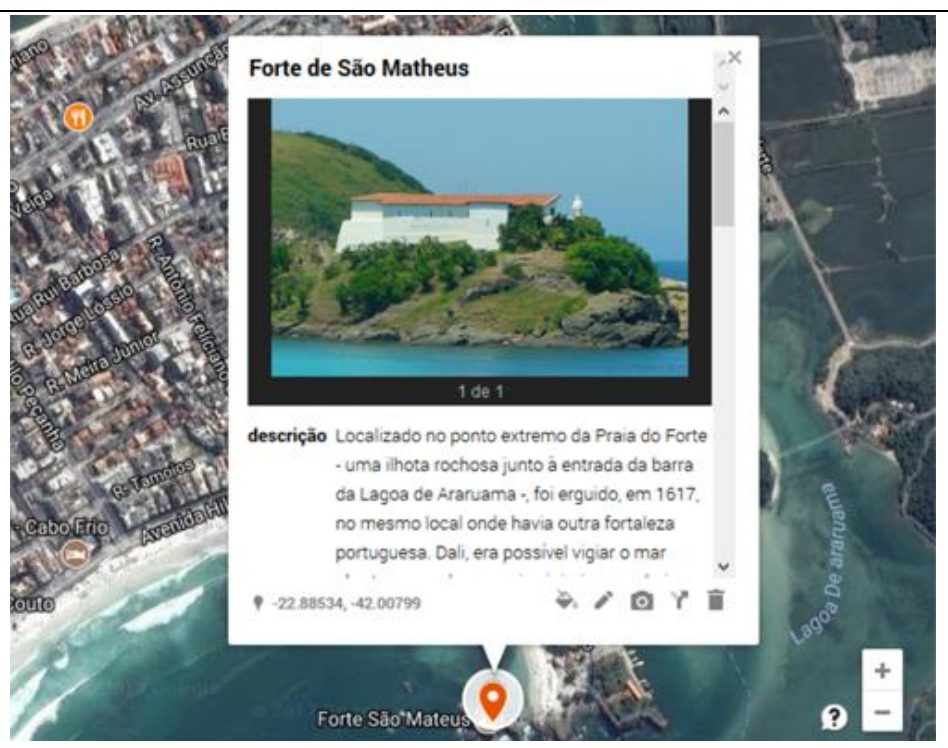

Figura 4. Tela do detalhe (imagem + texto)

Na Figura 5, visualiza-se uma sugestão de roteiro a ser realizado a pé. O roteiro percorre os registros contidos no mapa os quais sua visualização e indicação podem ser controladas pelo usuário.

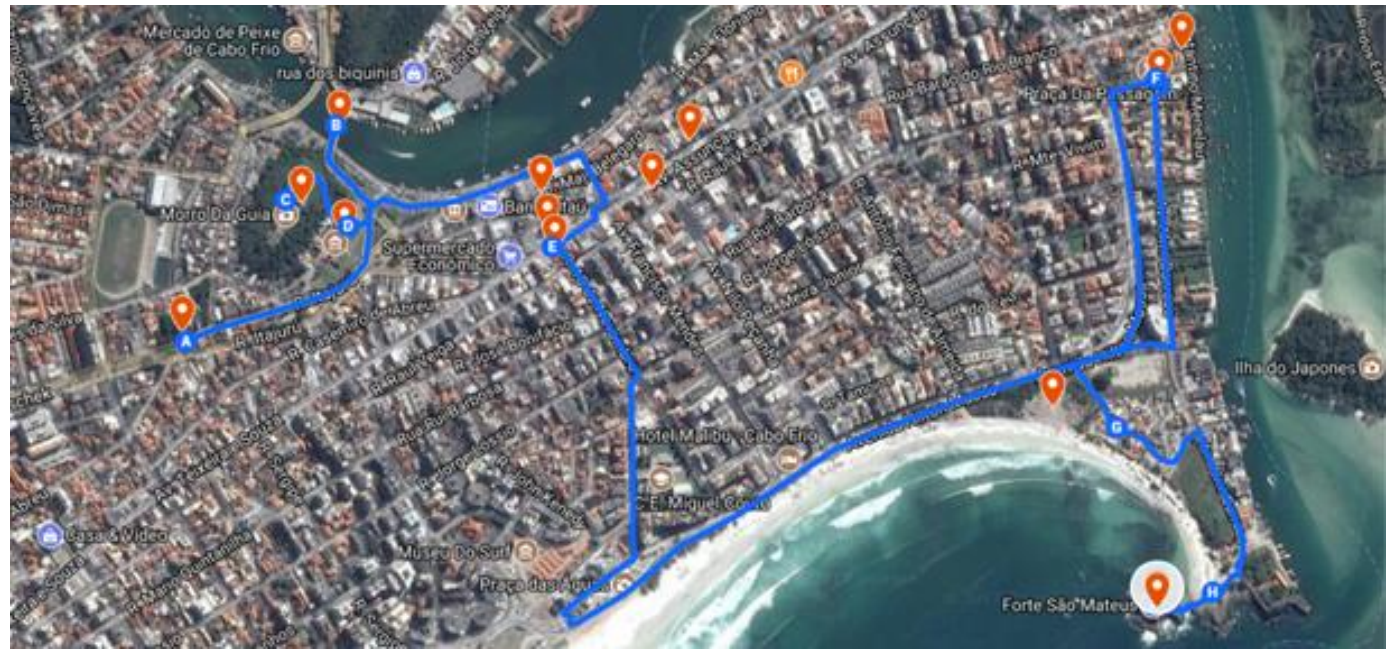

Figura 5. Opção de roteiro a pé.

Os protótipos de geovisualização e geocolaboração, a entender "o aplicativo YBY Cabo Frio e a plataforma de mesmo nome no Google Mymaps" foram disponibilizados na internet (https://drive.google.com/open?id=12JAiNNSH1f0ArrGqtYIWRsTpuRg), e no site (https://ybycabofrio.wixsite.com/projeto) para abrigar e difundir o trabalho.

As plataformas são gratuitas e demonstram a possibilidade de contribuir para a educação patrimonial fornecendo informações textuais, visuais e funcionalidades de geovisualização (conhecimento de pontos de interesse, visualização de imagens de satélite e melhor caminho entre pontos) mesmo com recursos financeiro limitados.

Com isso, oferece-se um suporte físico para apresentação de registros atemporais, tornando possível a inserção de novos registros pelos usuários por meio da geocolaboração. Com geocolaboração, os usuários compartilham novas visões, olhares, e interferências, integrando e participando do processo de educação patrimonial.

Os resultados mostraram que é possível de forma sistematizada e com baixo custo disponibilizar e divulgar o conhecimento do nosso patrimônio histórico-cultural e 
também vai se mostrar eficiente atendendo a interesses diversos, tais como, o repositório de informações, a preservação e o cuidado, a sinalização local, acessibilidade, visitas guiadas e temáticas, com guias qualificados abarcando principalmente estudantes e estagiários de diversas áreas do conhecimento educacional.

Mas cabe-nos a consciência de que um pesquisador não consegue, sem uma equipe de apoio ou sem uma associação de uma instituição do município, por exemplo, organizar informações e aplicá-las de diferentes formas, de tal maneira que o patrimônio seja realmente entendido, cuidado e apresentado, tanto para a população local, como para os turistas que esperam apenas o "turismo do sol".

Ao mesmo tempo, não devemos ficar apenas no campo das teorias, devemos lançar mãos de tais ferramentas e tecnologias, para uma maior aproximação e apropriação do espaço urbano a partir da esfera do vivido e das práticas cotidianas (FERRAZ, 2017).

\section{CONCLUSÕES}

O trabalho teve como objetivo divulgar, disponibilizar e popularizar o patrimônio histórico cultural da cidade de Cabo Frio, e, para atingi-lo utilizamos recursos de geoprocessamento (geovisualização e geocolaboração).

Mostramos como a geovisualização e a geocolaboração podem contribuir para a ampliação de novas formas de olhares sobre a cidade e seus bens materias ou imateriais, tanto em etapas de análise urbana ou em seu planejamento e gestão.

Ao fornecer meios para difundir pontos de interesse histórico-cultural da cidade de Cabo Frio-RJ, contribuímos para uma melhor gestão deste patrimônio através do amplo acesso à informação o que vai de encontro ao objetivo da pesquisa.

Com as informações disponibilizadas em ambiente Web, um maior número de pessoas interessadas poderá ter acesso aos locais, bem como ao conhecimento da história local. O reconhecimento do patrimônio é necessário para que visitantes e moradores locais entendam sua participação cidadã influenciando positivamente na construção de valores, identidades, consciência cultural e atuação para novas ações. A implementação de melhorias estimula o crescimento e novas atividades adicionam ao entretenimento já existente. Enfim, uma colaboração gera novos investimentos e não há como negar a importância dessa mola.

O desenvolvimento dos protótipos foi motivado pela importância históricocultural da cidade de Cabo Frio, sobretudo, à sua riqueza patrimonial que vem sofrendo constantes ameaças. Mas esses protótipos podem ser adaptados para outras realidades em outras áreas ou cidades. Desta forma, sugerimos que pesquisas futuras ajudem a integrar essa dinâmica espacial urbana. Pois acreditamos que dados que contiverem alguma informação faltando ou carentes de mais detalhes, deverão ser complementados por equipes interessadas no aproveitamento das ferramentas criadas e nos estudos já realizadas, ou na criação de novos.

\section{REFERÊNCIAS}

ALLEN, S.J. As Paisagens Desejadas e Imaginadas na Arqueologia da Cidade. Fundamentos, v. 11. pp. 86-103, 2014.

BARROS, M.C.; SERRA, H.H. A Belém da Belle Époque e Os Roteiros Geo-Turísticos como Instrumentos de Educação Patrimonial. Formação (Online), v. 25, n. 44, 2018.

BERANGER, A.F. Dados Históricos de Cabo Frio. Borsoi, 1962. 
BOWIE, G.D.; MILLWARD, A.A.; BHAGAT, N.N. Interactive mapping of urban tree benefits using Google Fusion Tables and API technologies. Urban Forestry \& Urban Greening, v. 13, n. 4, p. 742-755, 2014.

CABO FRIO. Projeto de Lei No017 /2018: Plano de Cultura do Município de Cabo Frio para o período de 2018 a 2027. [consulta: 10 de agosto de 2018]. Disponível em: http://webservice.npibrasil.com.br/wportal/arquivo.ashx?id=841f7d0d-6218-4acc-af16e5cc043d5ef7.

CARVALHO, G.A. Geoprocessamento aplicado à Gestão Urbana: Possibilidades e desafios. In: III Encontro de Geografia-VII Semana de Ciências Humanas, 2010.

CASTRO, C. A natureza turística do Rio de Janeiro. Turismo e identidade local: uma visão antropológica. Campinas, SP: Papirus, 2001.

CHRISTÓVÃO, J.H.O. A gênese do turismo em Cabo Frio, ou de como o sol se sobrepôs ao sal. In: Anais do XXVI Simpósio Nacional de História - ANPUH. - São Paulo, julho 2011.

CONCEIÇÃO SILVA, I.; DA SILVA, L.M.; DE ANDRADE FERNANDES, N.; JUNIOR, J.B.B.; CARVALHO, C.D.M.B. Reflexões Sobre a Utilização das Tecnologias no Processo de Ensino-Aprendizagem da Educação Patrimonial no Brasil. Revista Tecnologias na Educação, v.22, p. 1-12, 2017.

FERRAZ, C.B.R. Mapas Oficiais e Cartografias do Cotidiano: Tensionamentos das experiências no espaço. Cadernos de Pós-Graduação em Arquitetura e Urbanismo, v. 17, n. 2, p. 14, 2017.

GUALBERTO, M.; DA SILVA MARTINUCI, O.; LIBÓRIO, M.; LAUDARES, S. Sistemas Baseados em Localização: Uma Leitura Geográfica. Revista Espaço e Geografia, v. 20, n. 2, 2017.

GURGEL, H.C.A. Utilização das Geotecnologias em Estudos Epidemiológicos: O Exemplo da Relação entre a Malária e o NDVI em Roraima. In: Anais XI SBSR, Belo Horizonte, Brasil, 05 - 10 abril 2003, INPE, p. 1303 - 1310.

HANSSEN, G. Cabo Frio: dos Tamoios à Álcalis. Achiamé, 1988.

LAUDARES, S. Geotecnologia ao alcance de todos. Editora Appris. Curitiba, 2014.

MENEGUETTE, A.A.C. Cartografia no século 21: revisitando conceitos e definições. Geografia e Pesquisa, v. 6, n. 1, 2012.

MENEGUETTE, A.A.C. Geovisualização: aspectos conceituais. Universidade Estadual Paulista. Presidente Prudente, p. 01-04, 2014.

MOURA, A.C.M. Geoprocessamento na gestão do patrimônio histórico. Fórum Patrimônio: ambiente construído e patrimônio sustentável, v. 2, n. 1, 2013.

MOURA, A.C.M. Geotecnologias na interpretação da paisagem e gestão do patrimônio cultural. In: II Simpósio Brasileiro de Ciências Geodésicas e Tecnologias da Geoinformação. Recife-PE, 2008.

NAVARRO, E.A. Dicionário de tupi antigo: a língua indígena clássica do Brasil. São Paulo: Global, p. 573, 2013.

NEVES, M.S. Brasil, acertai vossos ponteiros. Rio de Janeiro, MAST, 1991.

PERES, O.M.; POLIDORI, M.C.; TOMIELLO, F. Patrimonio Cultural y SIG: escalas de visualización y preservación. Ciencias Espaciales, v. 8, n. 2, p. 41-58, 2015. 
RABELO, D.C.; ESPLUGA, J.; TEIXEIRA, E.C.; BRUGUÉ, Q. Citizenship participation in water management plans in the Doce River Basin, Brazil and Catalonia, Spain. Water Policy, v. 16, n. 2, p. 205-221, 2014.

RIBEIRO FILHO, G.B.; PASSOS, F.R.; MOURA PAULINO, C. Educação Urbana: construindo cidadania e sociabilidade em escolas municipais de Viçosa-MG. Revista de Educação Popular, v. 8, n. 1, 2010.

ROSA, R. Geotecnologias na geografia aplicada. Revista do Departamento de Geografia, v. 16, p. 81-90, 2011.

SILVA, J.K.; LIBÓRIO, M.P.; LAUDARES, S. Geovisualização da Arborização Viária Patrimoniada da Zona Central de Sete Lagoas-MG. Revista da Sociedade Brasileira de Arborização Urbana, v. 11, n. 3, p. 56-72, 2016.

TOLENTINO, Á.B. O que é Patrimônio Cultural para você? Em: TOLENTINO, Á.B. (org.) Educação patrimonial: reflexões e práticas. João Pessoa: Superintendência do Iphan na Paraíba, 2012. 